\title{
Redes sociais e preservação dos modos de produção de queijos artesanais da Ilha do Marajó, $\mathbf{P A}^{1}$
}

\author{
Benedito Ely Valente da Cruz \\ Universidade do Estado do Pará - Belém -Pará - Brasil \\ ORCID: http://orcid.org/0000-0002-5432-5105 \\ Elcio Costa do Nascimento \\ Universidade Federal do Rio Grande do Sul - Porto Alegre - Pará - Brasil \\ ORCID: http://orcid.org/0000-0003-0606-5940 \\ Fabiana Thomé da Cruz \\ Universidade Federal do do Rio Grande do Sul - Porto Alegre - Pará - Brasil \\ ORCID: http://orcid.org/0000-0001-8697-7362 \\ Miquéias Freitas Calvi \\ Universidade Federal do Pará - Altamira - Pará - Brasil \\ ORCID: http://orcid.org/0000-0002-9409-9915
}

\begin{abstract}
Resumo
Este trabalho objetiva refletir sobre redes sociais desenvolvidas ao longo do sistema de produção dos queijos (tipos manteiga e creme) do Marajó/PA, Brasil. Utilizando abordagem qualitativa, por meio de entrevista semiestruturada e história oral temática, buscou-se analisar e compreender as redes sociais desenvolvidas em torno da produção e consumo dos diferentes tipos de queijos do Marajó, os impactos na produção e na comercialização, suas características consideradas essenciais na manutenção e preservação de sua qualidade, visão dos produtores quanto às mudanças no processo produtivo, suas dificuldades, formas de resistência e permanência ao longo do tempo. Observou-se elevada importância social, econômica e cultural da produção dos queijos nas comunidades visitadas; relevância das redes sociais na definição da qualidade, na continuidade e manutenção da produção local; alta capacidade adaptativa dos produtores frente às elevadas exigências para atender à legislação, e a necessidade de políticas públicas que incentivem, preservem e fomentem a produção artesanal dos queijos do Marajó.
\end{abstract}

Palavras-chave: Saber-fazer tradicional. Queijo Artesanal. Qualidade. Produção Familiar.

\footnotetext{
${ }^{1}$ Uma primeira versão desse trabalho foi apresentado no II Workshop de Estratégias Alimentares e Abastecimento realizado nos dias 14 e 15 de setembro de 2019 na Universidade Federal do Rio Grande do Sul - UFRGS.
} 


\title{
Social network and preservation of the artisanal cheese production modes of the Island of
} Marajó, PA

\begin{abstract}
This work aims to reflect on the social networks developed along the cheese production chain (butter and cream) of Marajó / PA, Brazil. Using a qualitative approach, by semistructured interview and thematic oral histor, this paper sought to analyze and to understand social networks developed around the production and consumption of different Marajó cheeses, impacts on the production and commercialization, characteristics considered essential in maintaining and preserving their quality, the producers' vision to understand the contemporary production processes, their difficulties and ways of endurance and permanence over the years. The main findings suggested high social, economic and cultural importance of production in the visited communities as well as the relevance of social networks in preserving the quality, continuity and maintenance of local production; high adaptive capacity of producers in view of the demands to comply the legislation and the need for public policies that encourage, preserve and foster the artisanal production of Marajó cheese.
\end{abstract}

Keywords: Traditional Know how. Artisanal Cheese. Quality. Family production.

\section{Redes sociales y preservación de los modos de producción de quesos artesanales de la Isla del Marajó, PA}

\section{Resumen}

Este trabajo objetiva reflexionar sobre las redes sociales desarrolladas a lo largo de la cadena productiva de los quesos (mantequilla y crema) del Marajó / PA, Brasil. Utilizando un enfoque cualitativo, por medio de entrevista semiestructurada y historia oral temática, intentamos analizar y comprender las redes sociales desarrolladas en torno a la producción y el consumo de diferentes quesos Marajó, impactos en la producción y comercialización de queso, características consideradas esenciales para mantener y preservar su calidad, visión de los productores para comprender procesos contemporáneos de producción, sus dificultades, formas de resistencia y permanencia a lo largo de los años. Se observó una gran importancia social, económica y cultural de la producción en las comunidades visitadas; la relevancia de las redes sociales para preservar la calidad, continuidad y mantenimiento de la producción local; alta capacidad de adaptación de los productores en vista de las altas demandas para cumplir con la legislación y la necesidad de políticas públicas que fomenten, preserven y fomenten la producción artesanal de quesos Marajó.

Palabras clave: Saber hacer tradicional. Queso Artesanal. Calidad. Producción familiar.

\section{Introdução}

Os sistemas de produção, sejam alimentares ou de outros bens de consumo, vêm se modificando ao longo do tempo. Entretanto, principalmente, após a Revolução Industrial, os sistemas produtivos artesanais foram sendo gradativamente substituídos por sistemas industriais e, em decorrência, a pequena produção, pela grande escala (ARNAIZ, 2005; NIEDERLE, 2013). Esse contexto de mudanças se refletiu, e ainda hoje se reflete, em critérios de qualificação de produtos que, antes baseados por relações de proximidade e confiança, vêm sendo substituídos por critérios quantitativos, técnicos e científicos, embasados, via de regra, por selos e certificações (PREZOTTO, 2005).

Essa alteração incidiu nos critérios de avaliação da qualidade dos alimentos, refletindo em políticas públicas e legislações que assumem uma "qualidade" 
baseada em critérios métricos convencionais, ligados à produção de caráter industrial, deixando a pequena produção em segundo plano ou até mesmo na informalidade (WILKINSON, 1999; DORES; FERREIRA, 2012; CRUZ; MENASCHE, 2014; DREGGER, 2014). Entretanto, essa visão começou a ser amplamente questionada, colocando em cheque o modelo industrial convencional de produção até então sinônimo de alimentos com qualidade, livres de contaminantes, seguros e bons para a saúde (GOODMAN, 2003; PREZOTTO, 2005; LANG; BARLING; CARAHER, 2009; GOODMAN; DUPUIS; GOODMAN, 2012). Questionamentos que vêm aumentando nas últimas décadas devido a um variado conjunto de fatores, entre eles: o crescente acesso à informação, casos de contaminação alimentar devido o uso de insumos agrícolas; desconhecimento das práticas utilizadas na produção dos alimentos, "crises" alimentares relacionadas a doenças como o "mal da vaca louca"; questões ambientais e desigualdade social e econômica (FLORIT, 2004; GOODMAN, 2003; MENASCHE, 2010).

Esse contexto tem gerado amplo processo de (re)valorização e ressignificação do rural e de seus produtos, conotando a estes significados de confiabilidade, saudabilidade e transparência em relação as técnicas utilizadas e, portanto, capaz de fornecer alimentos seguros e saudáveis, acarretando na construção de demandas, novos mercados e padrões de consumo com forte ligação territorial e cultural (CRUZ, 2012; HARVEY; MCMEEKIN; WARDE, 2004; MENASCHE, 2010; NIEDERLE, 2013). Essa realidade possibilita o desenvolvimento de redes sociais de confiança que fortalecem e apóiam produtos e produtores locais, possibilitando a continuidade e a preservação de conhecimentos, técnicas de produção, modos de vida e produtos diferenciados e singulares, aspectos que, via de regra, têm sido negligenciados pelas normas de inspeção e fiscalização oficiais.

No caso dos queijos tipo manteiga e creme do Marajó - produzidos há aproximadamente dois séculos -, as motivações, alinhadas à valorização da produção artesanal, colaboraram para continuidade e resistência da produção local, principalmente após a intensificação das fiscalizações sanitárias, apreensão e proibição da comercialização de produtos alimentícios informais na região. A incidência dessas ações sobre empreendimentos considerados em desacordo com a legislação sanitária de produtos de origem animal acarretou perdas econômicas e sociais para produtores locais, ameaçou a continuidade da produção e reduziu o número de produtores de queijo que, como será evidenciado ao longo do artigo, optaram por continuar na atividade.

Considerando esse contexto, quais as consequências e impactos decorrentes da exclusão da pequena produção local e artesanal e da atuação de aparatos legais de fiscalização sobre as redes locais e sobre as características singulares dos queijos do Marajó/PA? Buscando responder tal questionamento, o objetivo desta pesquisa foi analisar as redes sociais em torno da produção e consumo dos queijos do Marajó, na construção de uma perspectiva relacional de um produto com qualidade. Para responder a esse objetivo, o artigo está divido em quatro partes. Além desta introdução e das considerações finais, que correspondem, respectivamente, a primeira e última seção do artigo, o texto apresenta, na segunda seção, os procedimentos metodológicos utilizados e o local do desenvolvimento da pesquisa. $\mathrm{Na}$ terceira seção, discute-se, à luz de conceitos como tradição, qualidade e confiança, o modo de produção dos queijos do Marajó, buscando evidenciar a 
importância das redes sociais na construção e fortalecimento dos queijos locais e na continuidade e preservação de seus modos de produção.

\section{Metodologia e Local de Estudo}

2.1 Área de estudo

A Mesorregião Geográfica do Marajó ${ }^{2}$ (IBGE, 1992), formada por dezesseis (16) municípios, tem área territorial aproximada de $104.140 \mathrm{~km}^{2}$, distribuída em três microrregiões geográficas (MRG): Arari, Furos de Breves e Portel. As duas primeiras compreendem municípios inseridos integralmente no Arquipélago do Marajó, enquanto a MRG de Portel abrange municípios com sedes em áreas continentais, na porção sul/sudoeste da mesorregião (Figura 1).

A pesquisa foi realizada na Microrregião do Arari, berço da pecuária de corte e leite da ilha de Marajó (LIMA, 1996), com enfoque nos municípios de Soure e Cachoeira do Arari (Figura 01).

Figura 1 - Mapa da Mesorregião do Marajó, suas microrregiões e local da pesquisa

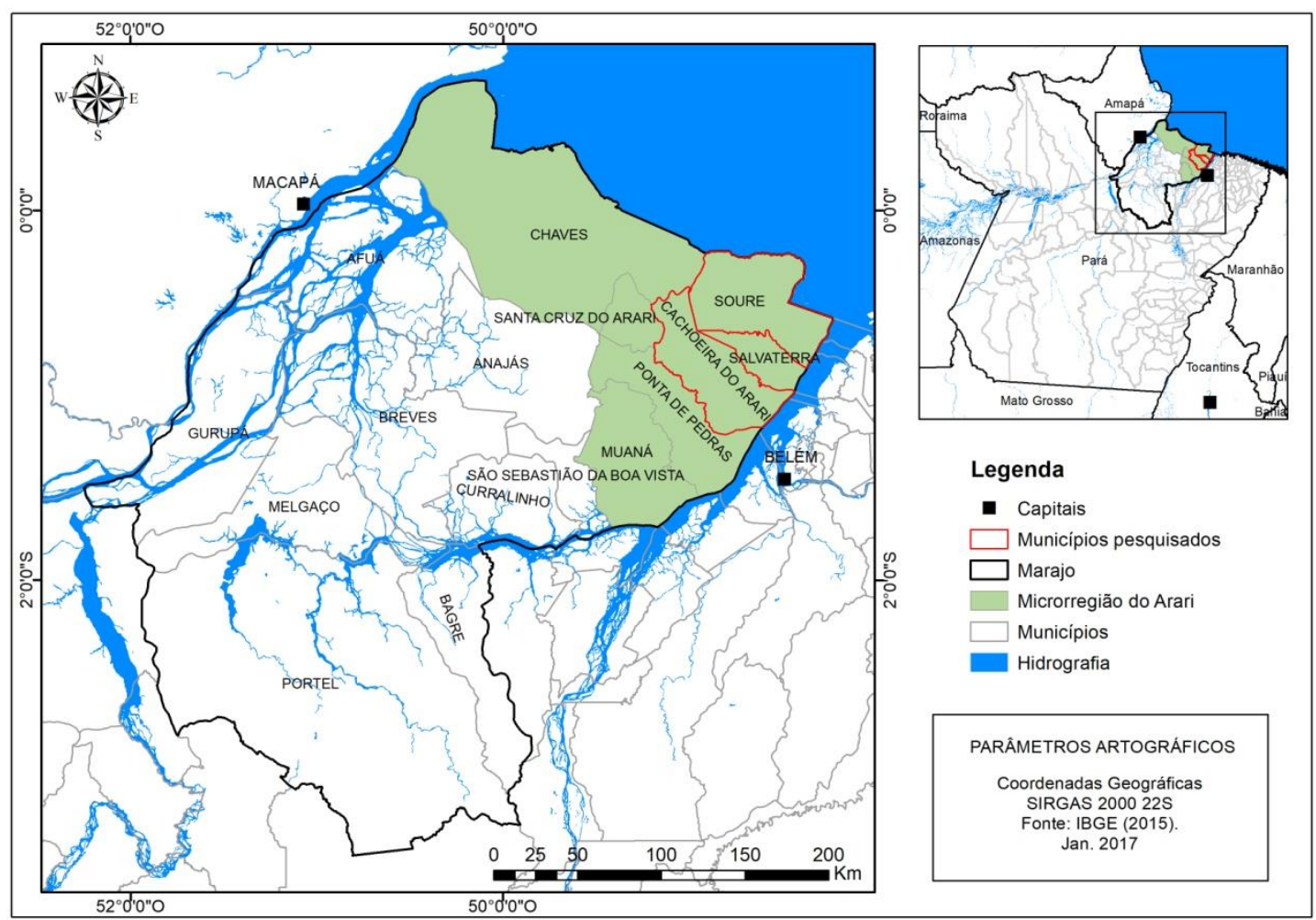

Fonte: Mapa elaborado de IBGE (2015).

${ }^{2}$ Para a continuidade deste trabalho, a Mesorregião do Marajó será referida como "Ilha de Marajó", utilizando a forma coloquial de referenciamento e, devido os municípios pesquisados encontrarem-se na MRG inserida integralmente no Arquipélago. 
Esses municípios se destacam como áreas tradicionalmente produtoras de queijo nessa Microrregião, pela história na produção e pela transmissão dos conhecimentos dos diferentes modos de produção que caracterizam e singularizam os produtos (FIGUEIRAS; QUADROS, 2002; SEIXAS et al., 2014; CRUZ, 2017).

\subsection{Geração e análise dos dados}

A geração de dados foi realizada no período de março a julho de 2016. Utilizando abordagem qualitativa, foram realizadas 15 entrevistas semiestruturadas com diferentes atores envolvidos na produção de queijo na região: quatro produtores de queijo creme e quatro de queijo manteiga (em atividade), queijeiro aposentado (1), representante da associação de produtores de queijo (1), exempregados de fazendas e queijarias da região (2) e consumidores de queijo (03). 0 perfil diferenciado dos entrevistados foi importante para obter informações sobre as diferentes características dos locais e modos de produção, as dificuldades enfrentadas, bem como sobre as redes sociais desenvolvidas ao longo do processo produtivo e de comercialização do queijo marajoara. A definição dos entrevistados que foram interlocutores desta pesquisa ocorreu em momentos distintos: primeiramente, atores de elevada estima e reconhecimento na região, devido as suas experiências e histórias como produtores/as, foram indicados e selecionados como fontes importantes para o alcance dos objetivos desta pesquisa e, posteriormente, foi solicitado a esses entrevistados indicações de outros informantes que poderiam contribuir para a realização da pesquisa de campo. As entrevistas foram feitas nas residências e/ou estabelecimentos agropecuários dos entrevistados, gravadas e, posteriormente, transcritas para auxiliar a análise de seu conteúdo.

As entrevistas semiestruturadas foram guiadas por perguntas-chave, porém abertas e fechadas, visando obter informações socioeconômicas básicas dos entrevistados (sexo, idade, grau de instrução, nome social), assim como estimulálos a falar abertamente sobre determinados assuntos, porém sem perder o foco da pesquisa. Buscou-se criar um ambiente confortável, no qual o entrevistado pudesse se expressar livremente, sem as limitações criadas por um questionário. Às entrevistas semiestruturadas foram associadas técnicas de história oral temática (MEIHY; HOLANDA, 2007), visando, através das memórias dos entrevistados, resgatar e subsidiar as informações sobre os modos de produção dos diferentes queijos locais. Buscou-se, por meio dessas técnicas de pesquisa "deixar ao recordador a liberdade de encadear e compor, à sua vontade, os momentos do seu passado" (BOSI, 1993, p. 283).

A história oral temática visou à obtenção de dados detalhados sobre a vida dos entrevistados, tendo como foco principal a história das famílias ligadas com a produção do queijo do Marajó e as formas de transmissão do conhecimento associado ao saber-fazer local. Dessa maneira, por meio de resgate histórico da produção e dos produtores, buscou-se compreender as redes sociais desenvolvidas em torno da produção e consumo dos queijos do Marajó, as características consideradas essenciais na manutenção e preservação da qualidade dos queijos locais. Todas as entrevistas, depois de transcritas, foram sistematizadas em categorias e analisadas por meio de análise de conteúdo (BARDIN, 1979). 


\title{
2. Tradição, Qualidade e Confiança na Produção dos Queijos do Marajó.
}

A história da produção do queijo do Marajó, atualmente reconhecido por ser produzido a partir de leite de búfala, remonta tempos anteriores à chegada dessa espécie na região, sendo feito originalmente com leite bovino. Relatos de produtores locais, assim como de produções acadêmicas (BARATA, 1973; MIRANDA NETO, 1976; LISBOA, 2012) e matérias de jornais (ESTADÃO, 2003; GLOBO RURAL, 2011) apontam para a existência da produção de queijos e manteigas na microrregião do Arari desde o século 18, existindo, portanto, há pelo menos 200 anos. Essa informação foi confirmada durante a realização da pesquisa, por meio de relatos obtidos de produtores de queijo mais antigos, empregados e exempregados de fazendas, com histórico na produção na região.

\begin{abstract}
Já se tinha queijo do Marajó, já se tinha fazenda que muito tempo antes, só que era leite bovino. Então há registro da produção do queijo do Marajó a mais de 200 anos de existência, antes mesmo da entrada do búfalo na ilha, nossos avós já faziam e quem fazia era os pais dele, só que não era de búfala (E1, queijeiro de Soure, 63 anos)
\end{abstract}

Na Ilha do Marajó, os principais queijos produzidos são do tipo manteiga e creme, sendo o primeiro produzido principalmente no município de Cachoeira do Arari e o segundo em Soure, Salvaterra, Ponta de Pedras e Muaná. O queijo tipo manteiga está na origem da produção dos diferentes tipos de queijos do Marajó. Após a inserção da desnatadeira na região, entre as décadas de 1920 e 1930, iniciouse a produção do queijo tipo creme e o processo de diferenciação.

Na década de 30, introduzimos a desnatadeira, e passamos a fazer o queijo tipo creme, com rendimento melhor, com qualidade melhor, e lá (em Cachoeira do Arari) eles não levaram, não compraram a desnatadeira, não acreditaram na desnatadeira e continuaram fazendo o queijo manteiga (E1, queijeiro de Soure, 63anos).

O queijo tipo manteiga é considerado mais rústico, enquanto o tipo creme, como o próprio nome sugere, é mais cremoso, sendo também conhecido como "requeijão" do Marajó. Esses queijos apresentam diferenças na textura, nível de produtividade e durabilidade (tempo de prateleira) (FIGUEIRAS; QUADROS, 2002). Essas diferenças são provenientes dos distintos saber-fazer territorializados.

Para que o queijo manteiga seja considerado de qualidade, há algumas operações fundamentais que, pela centralidade na qualidade do produto final, serão brevemente descritas aqui. Para produzir um quilograma de queijo manteiga (Figura 2) utiliza-se aproximadamente sete litros de leite de búfala. Após a ordenha, o leite cru é deixado em repouso em temperatura ambiente por 24 horas para coagular - diferente da maioria dos queijos artesanais do Brasil, de forma espontânea. Após esse período, é retirada a nata acumulada na superfície da coalhada, que é utilizada para a produção da manteiga. A massa é quebrada manualmente e depois prensada para retirada do soro, etapa realizada com o emprego de sacos de algodão. Drenado o soro, a massa prensada é levada ao fogo, aquecida com água e leite ordenhado no dia e mexida até ferver. A fervura por 
alguns minutos dá à massa consistência de "liga" característica ou o "ponto do queijo". Em seguida, a massa é prensada novamente para retirada do excesso de soro. Triturada a massa e adicionado o sal é então levada ao tacho para "fritar" na manteiga até ganhar a consistência desejada. Terminado o processo, o queijo é, atualmente, envasado à vácuo em embalagens plásticas de 200, 400 ou 500 gramas para ser comercializado, sob temperatura de refrigeração (FIGUEIRAS; QUADROS, 2002).

Figura 2 - Queijo do Marajó, tipo manteiga.

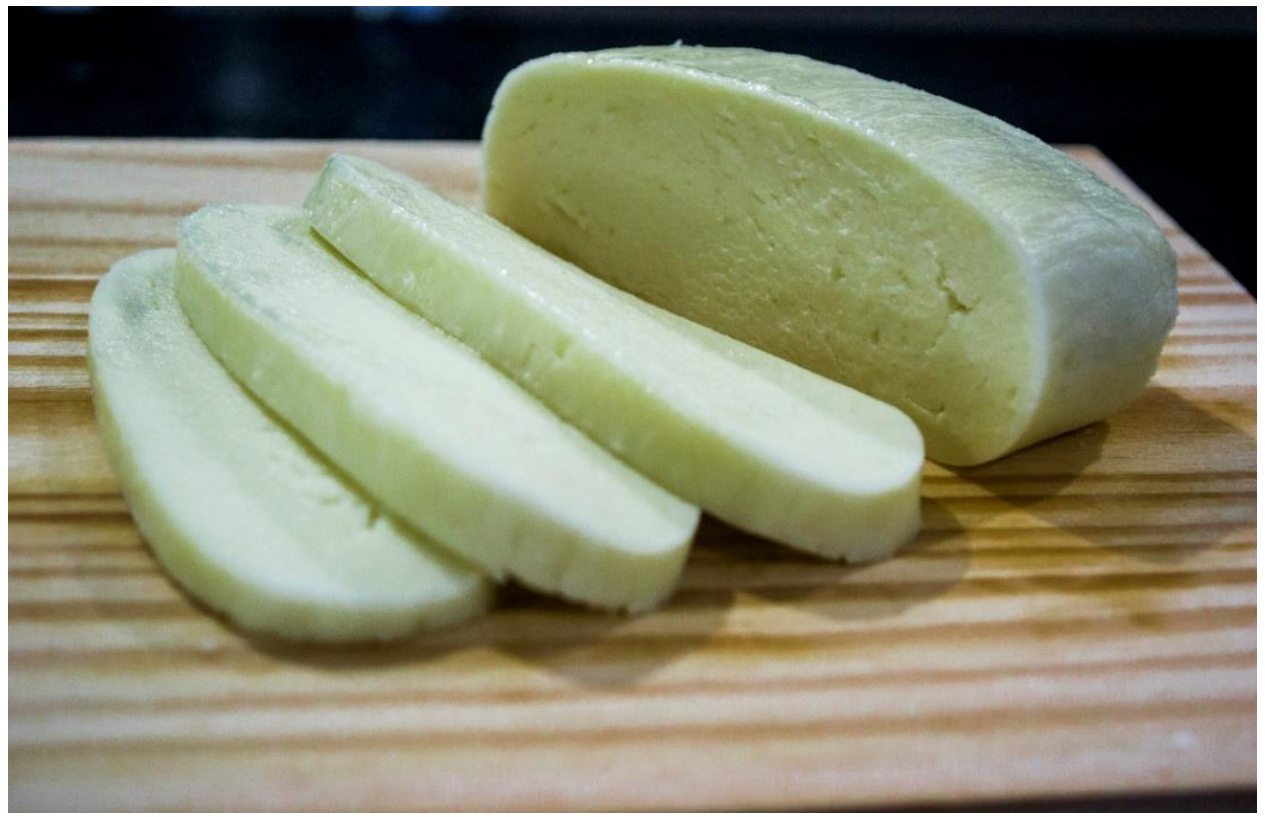

Fonte: Arquivo pessoal (2017).

Quanto às técnicas e práticas consideradas importantes para assegurar as características e qualidade final do produto, observou-se durante a pesquisa e nas falas dos entrevistados, a persistência do uso de equipamentos e utensílios considerados inadequados pelos órgãos de inspeção sanitária, que, no caso do Pará, se trata da Agência de Defesa Agropecuária do Estado do Pará (ADEPARÁ). Dentre esses utensílios, estão listados: a peneira de jacitara, feita a partir da fibra de uma planta local (Desmoncus polyacanthos Mart), a colher de pau, de mesas de madeira e do papel manteiga na embalagem. A continuidade no uso desses materiais é defendida pelos produtores que afirmam que a mudança afetaria a qualidade original do produto, alterando o sabor e o aspecto do produto.

A manutenção na forma de produção baseado no conhecimento tradicional demonstra o movimento de resistência desses produtores/famílias em preservar esse saber-fazer e, assim, garantir as características que diferenciam os queijos do Marajó.

Isso aí até hoje a gente ainda usa. O tacho de alumínio, a peneira de jacitara. Aqui a gente ainda trabalha com a peneira de jacitara, colher de pau. A ADEPARÁ ta modificando tem que ser do jeito que eles querem né, até a colher de pau eles querem mudar (E2, queijeiro de Cachoeira do Arari, 74 anos). 
Para a produção do queijo tipo creme do Marajó (Figura 3), do mesmo modo que mencionado em relação ao queijo tipo manteiga, a forma de fazer incide diretamente na qualidade do produto final. Por isso, ainda que brevemente, a seguir são descritas as operações principais que compõem o modo de fazer esse tipo de queijo. Inicialmente, o leite de búfala é colocado na desnatadeira para retirada da maior parte da gordura (80\%); em seguida, ele é colocado para "descansar" por período de 24 horas, no qual, do mesmo modo que acontece em relação ao processamento do queijo manteiga, sofre processo natural de coagulação. A coalhada ou massa passa pelo mesmo processo de preparação do queijo manteiga, sendo a massa quebrada e prensada para retirada do soro. Em seguida, a massa é levada ao fogo para aquecer com água, para redução da acidez, e com leite desnatado ordenhado no dia para aumento do volume da massa e incorporação de sólidos. Nesse processo, as partes sólidas e líquidas separam-se, e a parte sólida é levada para prensa, para retirada do soro restante. A massa "escorrida" é triturada para ser cozida novamente, etapa na qual é adicionado sal e o creme retirado pela desnatadeira. A massa é, então, mexida até a obtenção da consistência desejada. $O$ queijo creme é envasado e embalado da mesma forma que o queijo manteiga (FIGUEIRAS; QUADROS, 2002).

Figura 3 - Queijo do Marajó, tipo creme.

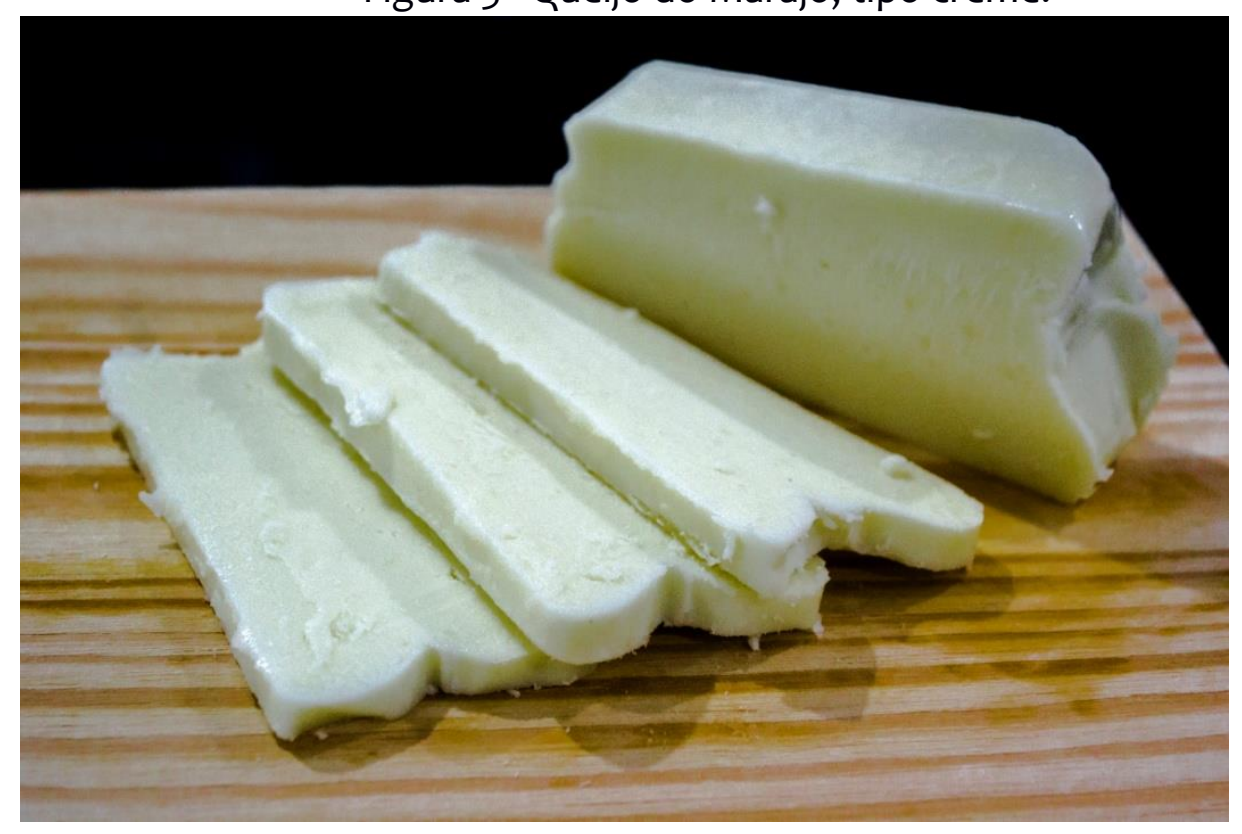

Fonte: Arquivo pessoal (2017).

No decorrer da pesquisa, observou-se que o sistema de produção do queijo do Marajó, tipo manteiga, é de caráter principalmente familiar, ocorre predominantemente em pequena escala e em pequenas propriedades rurais por meio da utilização de métodos simples, com pouco ou nenhum aparato tecnológico moderno e mão-de-obra de base familiar (pai, mãe, filho e parentes próximos). Realidade semelhante foi observada por Krone (2009), Dores e Ferreira (2012) e Cruz e Menasche (2014) em trabalhos de pesquisa sobre a produção de queijos artesanais em outras regiões produtoras no Brasil. Em relação às características socioeconômicas dos produtores entrevistados, a maioria eram homens com baixo 
nível de escolaridade, possuindo o ensino fundamental incompleto (até o $5^{\circ}$ ano) e idade elevada, entre 45 a 60 anos (75\%).

Entretanto, entre os produtores do queijo tipo creme, em Soure, a realidade se modifica, com a existência de médias e grandes propriedades, com presença de mão-de-obra assalariada e nível de escolaridade mais elevada (alguns proprietários possuem ensino superior). Informações similares foram observadas no mais recente censo agropecuário do IBGE (2017) nos municípios pesquisados, que demonstra um baixo nível de escolaridade e idade avançada (30 a 60 anos) entre os produtores locais de Cachoeira do Arari. Enquanto, em Soure, os produtores aparecem com um nível de educação mais elevado.

Essa realidade pode explicar algumas questões observadas em campo, como, por exemplo, o nível de capitalização mais elevada nos produtores do município de Soure, onde predomina a produção de queijo tipo creme. Esse aspecto pode ter relação com o maior grau de facilidade que estes produtores possuem quanto à adequação de seus sistemas produtivos e estabelecimentos às exigências ambientais e sanitárias vigentes no estado do Pará. Esses dados relacionados ao perfil dos produtores também foram constatados por Seixas et al. (2014) e Cruz (2017), evidenciando realidade persistente que tem influenciado o acesso à política de regularização das queijarias.

Isso pode ser evidenciado quando se analisa as queijarias licenciadas e com registros da ADEPARÁ. Nesse sentido, vale destacar que dos oito (08) produtores entrevistados (quatro de queijo creme e quatro de queijo manteiga), somente 01 queijaria (tipo manteiga) possuía a licença do órgão de fiscalização. Já as queijarias que produzem o queijo tipo creme todas se encontravam licenciadas. Cruz (2017), em pesquisa mais abrangente, observou que dos 39 estabelecimentos identificados, somente 10 estabelecimentos encontravam-se licenciados, sendo oito do queijo tipo creme e apenas dois do tipo manteiga.

Entretanto, apesar das diferenças de acesso a política de regularização, a produção dos diferentes queijos do Marajó, em especial do queijo tipo manteiga, persiste embalada, principalmente, por um conjunto de valores sociais que demandam produtos diferenciados, com forte identidade territorial, e a existência de redes sociais de confiança, com forte apelo ao tradicional/rural/artesanal e saudável.

Segundo Guerrero et al. (2010, p. 225), um produto reconhecido e/ou considerado tradicional é relacionado a termos que fazem alusão à família (na qual o indivíduo aprende os primeiros costumes, normas e regras de sociabilidade, transmitidos de uma geração para outra); às sensações (sabores, gostos e preferências); à herança (ancestral, cultural, antigo); à simplicidade (pouca industrialização); e à origem (associado a regiões, países). Nessa perspectiva, o produto tradicional está altamente vinculado à noção de tradição, a algo manuseado ou produzido de maneira mais "natural", com pouco ou nenhum processo industrial, onde a presença e participação da família são importantes, tanto para viabilizar a produção quanto para garantir sua perpetuação por meio das gerações, além de possuir identidade ligada a um determinado local (CRUZ, 2012; CRUZ; MENASCHE, 2014).

Nesse contexto, a produção do queijo do Marajó pode ser considerada de caráter tradicional, tendo em vista que apresenta as características mencionadas 
por Guerrero et al. (2010). Observou-se, nas falas dos entrevistados, a importância do âmbito familiar no processo de aprendizagem do saber-fazer o queijo e na transmissão de conhecimentos entre as gerações, assim como na viabilização da produção, tendo em vista que a principal fonte de mão-de-obra é a familiar.

Eu aprendi com o papai. Meu pai fazia queijo em casa, tirava, comprava leite e fazia queijo. Ele produzia, tinha alguma coisa, mas também comprava. Dai pra frente tinha que levantar cedo, tirar o leite, pra ajudar o papai a fazer o queijo pra poder fazer as outras coisas depois (E3, queijeiro de Cachoeira do Arari, 53anos).

Ele [pai] comprava leite, aí fazia o queijo no Jabuti, nós trabalhava com ele, aí que a gente aprendeu mais, porque a frequência foi mais do dia-adia (E2, queijeiro de Cachoeira do Arari, 74 anos).

Tanto para o queijo manteiga quanto ao queijo creme, pode-se argumentar que pessoas (produtores) e produtos possuem forte ligação com o lugar onde são produzidos e comercializados. O sistema de produção é simplificado e preserva modo tradicional de produção que, em sua maioria, é realizado em pequenas queijarias localizadas nos arredores das propriedades (Figura 04) ou ainda nas cozinhas das casas, fazendo uso de equipamentos e utensílios simples e rústicos, com pouca ou nenhuma automação ou mecanização.

Figura 04 - Pequena queijaria familiar no município de Cachoeira do Arari.

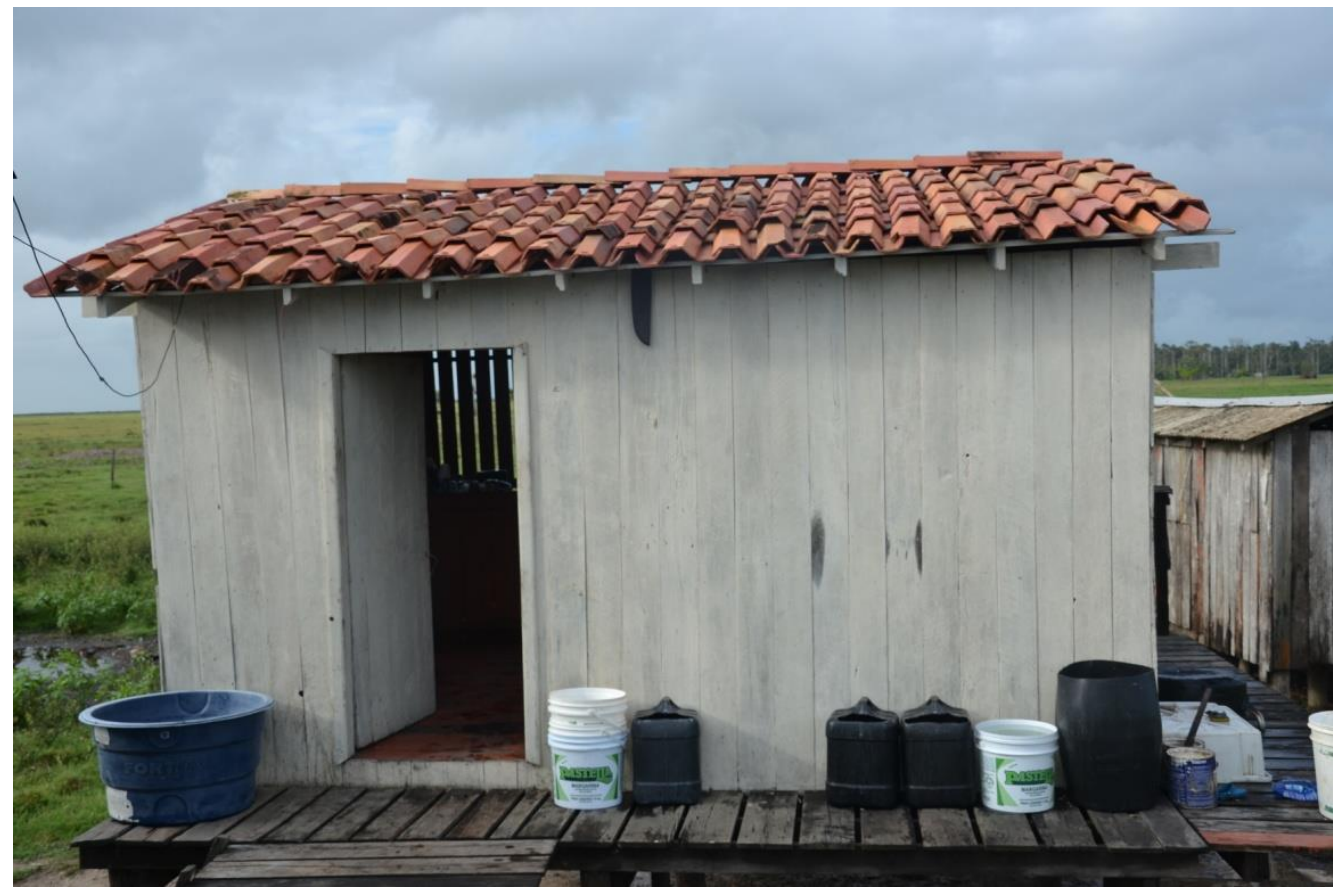

Fonte: Arquivo pessoal (2017).

Essa tradição é preservada, principalmente, pelos "guardiões" existentes na microrregião do Arari. Cruz (2012) considera como "guardiões" os produtores que detêm tanto o conhecimento do modo de produção quanto à reputação entre os membros da comunidade. No caso dos queijos do Marajó, essas características foram adquiridas ao longo dos anos de experiência e prática na produção, 
preservando o saber-fazer culturalmente reconhecido entre os produtores e consumidores, inserindo inovações e adaptações quando necessário, porém sem perder as características artesanais e as singularidades que torna o produto único e inconfundível.

Dentre os produtores considerados "guardiões" do saber-fazer do queijo, reconhecidos como os detentores desse conhecimento, o entrevistado E2 (de Cachoeira do Ararí) e a entrevistada E4 (de Soure) são amplamente reconhecidos tanto localmente quanto por queijeiros "profissionais", de fora. Esse reconhecimento decorre da experiência adquirida na prática diária, prática que faz do cotidiano uma escola que crescentemente qualifica a arte de fazer o queijo do Marajó, desenvolvendo conhecimentos, técnicas e práticas próprias voltadas para a qualidade do produto final.

\footnotetext{
Porque esse nosso modo de trabalhar é tudo assim por prática né, não tem nada por técnica. $O$ sal a gente coloca sem medo, o leite sem medir, o ponto também. A gente conhece por conhecimento, quando tá bom, quando não tá (E4, ex-produtora de queijo de Soure, 78 anos).

Uma vez veio um senhor dar aula de derivado do leite [...], tinha vários queijeiro lá, na hora eles apontaram pra mim né, pra ver se eu conseguia fazer. (E2, queijeiro de Cachoeira do Arari, 74 anos).
}

Produtores com tais níveis de conhecimentos são contatados por outros queijeiros para prestar orientações e, eventualmente, inclusive "salvar" a produção quando se deparam com dificuldades para "acertar" ou obter o "ponto" certo dos queijos. Entre os relatos obtidos, foi comum a alusão a produtores/as que sabiam reconhecer, nas várias etapas do processo de produção dos queijos, inclusive no momento da ordenha do leite, se o produto final, o queijo, seria de boa ou má qualidade, bastando, para isso, apenas observar as características da matéria prima para obter tal diagnóstico, situação referenciada por um dos interlocutores da pesquisa.

Os "guardiões" são os responsáveis não somente pela preservação do saberfazer dos queijos, como também são requisitados para "desenvolver" técnicas que possam melhorar a produção e/ou diminuir perdas durante o processamento, assim adaptam e reciclam práticas já existentes. No município de Cachoeira do Arari ocorreram vários relatos nesse sentido, com alusão à importância do entrevistado E2 no desenvolvimento de ideias voltadas a melhorar ou qualificar a arte de fazer o queijo, observando, testando e aprimorando o modo de fabrico.

O E2 era um dos "cara" que inventava junto com a gente. Se tava perdendo, bora vê se a gente dá um jeito [...]. Quando dava problema nos queijos dos vizinhos, quando não era o E2 era eu que ia ajeitar. Era assim que a gente fazia, um ajudava o outro, pra dá jeito (E3, queijeiro de Cachoeira do Arari, 53 anos).

A fala do entrevistado E3 demonstra a existência de conhecimento técnico evolutivo, que se aprimora ao longo do tempo. Esse conhecimento é adquirido, segundo Fonte (2008, p. 210), "através de circunstâncias experienciais particulares e transmitidas por 'especialistas locais' em situações informais de aprendizagem". Ainda que o autor esteja referindo às formas tradicionais de produção e 
processamento de alimentos no contexto de alguns países europeus, tal análise se aplica ao caso marajoara da produção queijo, onde as "situações informais" das atividades cotidianas aparecem como principais formas de repasse de conhecimento entre as gerações. Fonte (2008) conceitua esse conhecimento adquirido informalmente como "conhecimento leigo", o qual se difere do conhecimento técnico devido ao seu caráter não padronizado ou "cientificamente" não aceito e/ou reconhecido, razão pela qual essa forma de saber ser inferiorizada e até mesmo deslegitimada, ganhando status de atrasada e estática.

Cruz (2012, p. 60) afirma que "o caráter repetitivo da tradição não significa que suas práticas sejam estáticas". Elas sofrem "mudanças e alterações ao longo do tempo", de acordo com as necessidades, levando em consideração vários fatores que afetam a qualidade do produto, demonstrando a existência de uma "ciência" localmente desenvolvida. A troca e a disseminação desse conhecimento possibilitou que a arte de fazer os queijos na llha do Marajó se reinventasse e se adaptasse às necessidades dos/as produtores/as e da região, assegurando sua continuidade, gerando renda e desenvolvimento socioeconômico e cultural das famílias envolvidas nessa cadeia produtiva.

O queijo, pra quem não sabe mesmo, ele tem muita ciência, se passar do ponto ele fica duro, ele fica farinhento (E2, queijeiro de Cachoeira do Arari, 74 anos).

Os dados apresentados evidenciam que trata-se, portanto, de um sistema produtivo de elevada capacidade de adaptação e resistência por parte dos produtores locais. Tais características se intensificaram nas últimas décadas, quando os queijos artesanais do Marajó passaram a ter sua produção restringida, como será abordado na próxima seção.

2.1. Tradição ameaçada: proibições e perspectivas para os queijos artesanais do Marajó

As ameaças ao queijo do Marajó remetem-se a década de 1990, quando da criação da ADEPARÁ e da intensificação da fiscalização sanitária que incidiu sobre a produção e comercialização dos queijos produzidos no Marajó. A ausência de legislação que amparassem os queijos artesanais levou a apreensões de produtos, dificultando a comercialização, principalmente para estabelecimentos da capital do estado, Belém, principal destino da produção. Dois entrevistados na pesquisa descrevem a fiscalização, como evidenciam os trechos a seguir.

Em 1995/7 começou a fiscalização, não deixava a gente passar, a gente colocava quatro (04) lata naquelas sacas de fibra e saia naquele comércio. Aí depois que começou o transporte aqui pelo [porto do] Camará e as nossas embarcações pequenas pararam, a gente já ia pelo navio. Ai, lá no porto de Belém pegou mais ainda, que lá eles tomavam mesmo o queijo da gente, inclusive meu, eles pegaram duas vezes (E3, queijeiro de Cachoeira do Arari, 53 anos).

Uma vez, me prenderam queijo lá [em Belém], só uma vez só. Uns 70/80 quilos de queijo. Mas eu tinha conhecimento lá, aí um cara conseguiu devolver pra eu trazer o queijo de volta pra cá (E2, queijeiro de Cachoeira do Arari, 74 anos). 
Esta situação perdurou até 2013 quando entrou em vigor a Portaria $\mathrm{n}^{\circ} 418$ de 04 de março de 2013 (PARÁ, 2013) , $^{3}$ que regulamentou a produção de queijo do Marajó. Nesse longo período, o produto ficou na informalidade e seu mercado restringiu-se predominante a ilha de Marajó. De uma atividade econômica em ascensão econômica e de grande valor cultural, com o passar do tempo foi perdendo relevância e espaço na economia marajoara.

O marco regulatório que possibilitou a formalização do queijo do Marajó e de outros produtos tradicionais no estado do Pará está inserido no aumento de movimentos críticos ao sistema de produção convencional de alimentos e de suas consequências à saúde humana e ao ambiente (LANG; BARLING; CARAHER, 2009; GOODMAN; DUPUIS; GOODMAN, 2012) e como outros que pautam a (re)valorização da produção local e artesanal (HARVEY; MCMEEKIN; WARDE, 2004), contribuindo, assim, para o crescimento de movimentos e debates em favor do reconhecimento de alimentos artesanais. Como consequência desses fatores, um conjunto de normativas passou a ser implementado nas diferentes esferas governamentais ${ }^{4}$, dentro das quais, como pioneiro nessas mudanças, está a criação, em 2006, do Sistema Unificado de Atenção a Sanidade Agropecuária - SUASA (BRASIL, 2006), regulamentado pelo Decreto $\mathrm{n}^{\circ} 5 \cdot 741 / 2016$, que reduziu as restrições para a comercialização interestaduais e intermunicipais de produtos de origem animal e tornou possível a atuação integrada dos diferentes órgãos de inspeção sanitária, nas três esferas do poder público (CRUZ, 2020). Se devidamente implementado, esse Sistema permite que o produto artesanal inspecionado por uma das três instâncias de inspeção (municipal, estadual ou federal) seja comercializado em todo o território nacional, derrubando, de certa maneira, a barreira geográfica e permitindo pleno acesso aos mercados locais e mais distantes.

Nesse sentido, vale ressaltar a promulgação da Lei Federal $n^{\circ} 13.680$, de junho de 2018 (BRASIL, 2018), regulamentada pelo Decreto $n^{\circ}$ 9.918/2019 (BRASIL, 2019a), que altera aparatos legais que dificultavam a produção e a comercialização de produtos artesanais (como a Lei n 1.283/1950 - RIISPOA) (BRASIL, 1950; 1952), desburocratizando o processo de inspeção sanitária, igualando os serviços de inspeção municipais (SIM), estaduais (SIE) e o federal (SIF), ao selo ARTE. Entretanto, não esclarece questões relacionadas às "boas práticas" agropecuárias e sobre as "normas sanitárias e regulamentos" necessários na definição de um produto inócuo (art. $6^{\circ}$ ).

Contudo, apesar dessas "novas" legislações reconhecerem a importância da produção artesanal, outros critérios que dificultam a atuação e a participação dos/as produtores/as artesanais e de pequena escala no mercado formal ainda

\footnotetext{
${ }^{3}$ A Portaria $n^{\circ} 418$ de 04 de março de 2013, tem amparo na Lei $n^{\circ} 7.565$ de 2011, Decreto $n^{\circ}$ 480 , de 12 de julho de 2012 e Decreto $n^{\circ} 1.380$, de 3 de setembro de 2015, que regulamentam a produção e comercialização de produtos aartesanais no estado do Pará.

4 À exemplo dessas normativas, o Governo do Pará, também promulgou, através da ADEPARÁ, a Portaria $n^{\circ} 418$ de 2013 (PARÁ, 2013), que aprova o regulamento técnico de produção do queijo do Marajó e dá outras providências; e ao Ministério da Agricultura, Pecuária e Abastecimento (MAPA), que publicou a Instrução Normativa $n^{\circ} 30$ de 2013 (BRASIL, 2013), que permite a comercialização de queijos artesanais com maturação menor que 60 dias e o uso de leite cru (não pasteurizado) no processo produtivo.
} 
permanecem em vigor. Como exemplo, vale mencionar que, em que pese os regulamentos mais recentes, ainda há necessidades de adequação de alguns aspectos da produção do queijo artesanal às exigências do RIISPOA, publicado originalmente em 1950 (BRASIL, 1950; 1952), revisado em 2017 pelo Decreto $\mathrm{n}^{\circ}$ 9.013/2017 (BRASIL, 2017) e Instrução Normativa $N^{\circ}$ 73, de 23 de dezembro de 2019 (BRASIL, 2019b), que estabelece os parâmetros sanitários para a concessão do Selo Arte.

Apesar da revisão, pouca coisa mudou em relação à produção artesanal e determinadas demandas persistem, com complexas e onerosas exigências que vão desde as etapas de produção, processamento e comercialização, incluindo detalhamento das instalações das queijarias, dos materiais utilizados e de exames que devem ser realizados periodicamente pelo produtor, visando maior controle da qualidade sanitária do produto.

Nesse contexto, o nivelamento da importância dos serviços de inspeção municipais, estaduais e federal não facilitou o acesso aos registros e selos por parte da pequena produção artesanal, tendo em vista o elevado custo para a adequação de seus estabelecimentos aos padrões legais, permanecendo o favorecimento as grandes corporações de alimentos, em detrimento das pequenas produções, maiores afetadas pelas instituições vigentes.

Exemplo dessa realidade e do peso das exigências normativas é o reduzido número de empreendimentos familiares registradas da região do Marajó, pela ADEPARÁ, apenas 10 queijarias, como mencionado anteriormente, e dessas apenas $01 \mathrm{com}$ registro de Selo Arte ${ }^{5}$. O elevado custo para adequações estruturais e de exigências de laudos que comprovem a potabilidade da água utilizada; a qualidade microbiológica e físico-química do leite cru; análise físico-química e microbiológica do queijo produzido, entre outros, estão entre os principais entraves enfrentados pelos produtores de pequena escala para obtenção do licenciamento (CRUZ, 2017; PARÁ, 2013).

\begin{abstract}
Muita gente não tem condição de fazer uma queijaria do jeito que eles [ADEPARÁ] querem. No mínimo, é 20, 30 mil reais. Eles querem que o cara [produtor] faça sem condição, a despesa, o investimento é alto pra renda que ele tem (E2, queijeiro de Cachoeira do Arari, 74 anos).

O produtor Paulinho gastou aí o seus quase 60/70 mil pra ajeitar aquela queijariazinha dele lá. Ou seja, pra quem vive só daquilo ali é muito caro. Então, a ADEPARA ela foi, ela nos pressionou muito mesmo e quem começou a nos tomar queijo na verdade foi a ADEPARA lá em Belém (E3, queijeiro de Cachoeira do Arari, 53 anos).
\end{abstract}

Essas dificuldades e o aumento da fiscalização por parte dos órgãos sanitários têm, em certa medida, inviabilizado e desestimulado a produção desses queijos tradicionais, principalmente do tipo manteiga que, no caso de algumas famílias, culminou na paralização da atividade, forçando os produtores a redirecionarem suas práticas produtivas (tornando-se fornecedores de matériaprima para as queijarias de maior porte que possuem o licenciamento e o registro estadual).

\footnotetext{
${ }^{5}$ Queijaria localizada no município de Salvaterra e produtora do queijo do Marajó tipo creme.
} 
Mas nesse período da ADEPARA funcionar mais como polícia, de chegar lá, intimidar, ir lá, isso inibiu, engessou, muita gente deixou de fazer queijo. Nós que produzimos queijo há muito tempo, nós diminuímos nossa produção também, ficamos aqui, muito timidamente, vendendo mais aqui (E1, queijeiro de Soure, 63 anos).

Em outras situações observadas, algumas famílias tendem a reduzir a produção e diversificarem suas atividades e/ou permanecer na informalidade, comercializando sua produção para uma clientela que demonstra uma predileção por seus produtos, desenvolvida através de laços de confiabilidade entre o produtor e consumidores. Nesse processo, vale destacar a complexa rede social desenvolvida e mantida entre produtores e consumidores do queijo marajoara, consistindo na preferência por determinados produtos, considerados de "melhor sabor" e "melhor consistência", assim como as preferências por queijos de determinados produtores, devido à qualidade apresentada e requisitada por seus consumidores.

Eu só não parei de fazer queijo, porque, além de me ajudar né, mas tenho assim um certo conhecimento de tanta gente, que eles procuram muito $o$ meu queijo (E2, queijeiro, 74 anos, Cachoeira do Arari).

Murrieta (2001), em estudo sobre as escolhas alimentares de uma população ribeirinha do estado do Pará, analisa um conjunto de aspectos utilizados para definir produto de "boa" e "má" qualidade, o que reflete, segundo o autor, diretamente nas escolhas dos consumidores, que se pautam em características socialmente desenvolvidas e na ligação com o território, cultura e tradição. Portanto, características ligadas ao sabor, textura, aparência e odor são operacionalizados na distinção e, consequentemente, na escolha dos "melhores" e "piores" produtos, que permite, inclusive, indicar o produto resultante de um processo produtivo negligente. Durante a pesquisa sobre os queijos, constatou-se realidade semelhante à observada por Murrieta (2001), ou seja, de escolhas e predileções a determinados produtos e/ou produtores a partir de características específicas desejadas e apreciadas no produto final.

Eu parei que comer queijo, o E3 parou [...]. Já provei todos, um pouquinho de cada, sabe, mas não é a mesma coisa (Consumidora entrevistada no porto do Camará, Salvaterra).

Goodman (2003) alude sobre o crescimento de um movimento de valorização da produção local, considerada mais confiável e saudável, em detrimento da produção industrial, padronizada e de massa. Esse movimento, denominado pelo autor como quality turn, baseia-se em convenções e valores diferenciados, que vão além das instituições formais (leis, portarias etc.) e questões técnicas e quantitativas, fortalecendo a produção local e estimulando formas de organização econômicas diferenciadas, locais e socialmente justas. No caso do queijo do Marajó, o contexto mais recente tem permitido e promovido a continuidade da produção e a preservação de um modo de produção tradicional, com características fortemente ligadas a um saber-fazer tradicional, fortemente ligado a um território e possuidor de modo de produção (simplificado, mais confiável), que reflete nas decisões, escolhas e predileções dos consumidores, baseadas em características desejadas e apreciadas no produto final. 
Influencia na cor, influencia no gosto. Esse perímetro nosso aqui, envolvendo Jabuti, Retiro Grande, Gurupatuba, eu não tenho susto de fazer queijo do leite daí. Pode botar que eu faço, agora tem a diferença do leite que já vem dali do urubu, ali pra perto de Cachoeira já, dá uma diferença (E4, queijeiro, 74 anos, Cachoeira do Arari)

Assim, seguindo tanto discussões de caráter mais teórico quando os dados empíricos da pesquisa realizada sobre os queijos do Marajó, pode-se afirmar que o termo "qualidade" assumi múltiplas dimensões, muitos significados e, além disso, ser constituído por meio de relações entre os autores envolvidos (CRUZ; MENASCHE, 2014), tornando-os agentes importantes na construção de redes sociais de valorização de alimentos locais (FONTE, 2008).

A construção e/ou relativização do que é considerado ou entendido como um produto de "qualidade" está fortemente relacionado com o consumo de produtos em relação aos quais as "técnicas e métodos de produção são conhecidos, histórico e socialmente legitimados" (CRUZ; MENASCHE, 2014 p. 11). Noções como tradição, território e cultura são inseridos nesse processo de qualificação, demonstrando a complexidade dessa construção, socialmente desenvolvida, a qual não pode, simplesmente, ser mensurada por aparatos normativos formais que não levam em consideração a realidade e as relações localmente existentes, que são responsáveis pelo fortalecimento de relações que definem predileções e escolhas por certos produtos (e produtores) em relação a outros.

Nesse contexto e perspectiva de análise, a qualidade é analisada a partir de forte cunho social, o que possibilita a formação de redes locais de comercialização, assegurando aos produtores de queijo locais, com suas queijarias tradicionais, mesmo não licenciadas, continuarem produzindo e comercializando seus produtos, por meio da construção e manutenção de laços de confiança em relação ao produto e aos seus atributos de qualidade. Isso tem gerado a fidelização de crescente clientela e assegurado o destino de parte significativa da produção do tradicional queijo do Marajó.

\section{Considerações Finais}

Neste artigo, em que analisamos a produção do queijo do Marajó em suas diferentes formas (tipo creme e manteiga), procuramos evidenciar a importância deste produto na região dos campos marajoara, tanto em nível econômico, quanto histórico, cultural e social. Com elevado vínculo territorial, a produção de queijos no Marajó movimenta a economia local, gera trabalho, renda e desenvolvimento, possibilitando a permanência e reprodução social e econômica de diversas famílias na região.

Porém, a mudança do marco regulatório relacionado à produção e comercialização de produtos artesanais e as dificuldades impostas pelas normas sanitárias, fiscais e tributárias em vigor, têm afetado a realidade local, modificando lógicas e práticas produtivas que possuem forte apelo cultural, territorial e social. Não se trata, contudo, de não haver orientações quanto à forma de produção, especialmente no que diz respeito à questão sanitária, mas sim da postura que, via de regra, a ação fiscalizatória adota, qual seja, a de desvalorização ou de deslegitimação desse conhecimento que, por ser informal ou não científico, é 
caracterizado como atrasado, estático e que, consequentemente, deve ser "modernizado" para ser aceito e reconhecido.

Entretanto, paralelamente a deslegitimação de formas tradicionais e artesanais de processamento de alimentos, há também forte "movimento" de valorização desses produtos, tendo como agentes fundamentais os consumidores. Esse movimento, na direção contrária aos princípios que emanam do RISPOA, tem possibilitado resistência por parte de famílias produtoras e estimulado a continuidade de suas práticas produtivas, de seus produtos e de seu modo de vida.

A ampliação da noção do que é produto de qualidade tem sido a base para esse recente contra-movimento. Lança-se um conjunto de aspectos para essa (re)definição que vão além de critérios técnicos/científicos ou questões vinculadas às normas legais vigentes de sanidade e de "risco" zero. Incorporam-se aspectos locais socialmente conhecidos e reconhecidos, entre os quais textura, sabor, territorialidade, laços de confiança, entre outros, possibilitando o fortalecimento de uma rede social complexa de produtores e consumidores que permite a continuidade de modos de produção culturalmente reconhecidos e economicamente importantes.

Essa recente "onda" ou movimento de valorização de alimentos tradicionais e artesanais tem influenciado mudanças importantes na legislação, reconhecendo esses modos de produção característicos e conhecimentos que precisam ser preservados, garantindo a diversidade de práticas e lógicas produtivas. Reforçamse, assim, processos que podem possibilitar a continuação da produção de queijos artesanais no Brasil, entre as quais a dos queijos do Marajó e de seus aspectos e características singulares. Nesse sentido, há necessidade de pesquisas que resguardem as formas de fazer tradicionais do queijo do Marajó para que o mesmo não perca sua originalidade e singularidade.

\section{REFERÊNCIAS}

ARNAIZ, M. G. Em direção a uma Nova Ordem Alimentar? In: CANESQUI, A. M; GARCIA R. W. (Orgs). Antropologia e nutrição: um diálogo possível. Rio de Janeiro: Editora FIOCRUZ, p. 147-164 2005.

BARDIN, L. Análise de Conteúdo. Lisboa: Edições 70, 1979.

BRASIL. Lei $\mathbf{n}^{\circ} \mathbf{1 . 2 8 3}$, de 18 de dezembro de 1950. Dispõe sobre a inspeção industrial e sanitária dos produtos de origem animal. Diário Oficial da República Federativa do Brasil. Brasília. 19 dez. 1950.

Decreto n 30.691 , de 29 de março de 1952. Aprova o novo Regulamento da Inspeção Industrial e Sanitária de Produtos de Origem Animal. Presidência da República, Casa Civil. 29 mar. 1952.

. Decreto ${ }^{\circ}$ 5.741, de 30 de março de 2006. Regulamenta os arts. 27-A, 28-A e 29-A da Lei no 8.171, de 17 de janeiro de 1991. Organiza o Sistema Unificado de Atenção à Sanidade Agropecuária, e dá outras providências. Diário Oficial da União. Brasília. 31 mar. 2006. 
. Instrução Normativa do MAPA $n^{\circ}$ 30, de 07 de agosto de 2013. Permite que os queijos artesanais tradicionalmente elaborados a partir de leite cru sejam maturados por um período inferior a 60 (sessenta) dias. Diário Oficial da União. Brasília. 08 ago. 2013.

. Decreto $n^{\circ} \mathbf{9 . 0 1 3}$, de 29 de março de 2017. Regulamenta a Lei $n^{\circ} 1.283$, de 18 de dezembro de 1950 , e a Lei ${ }^{\circ} 7.889$, de 23 de novembro de 1989, que dispõem sobre a inspeção industrial e sanitária de produtos de origem animal. Diário Oficial da União. Brasília. 30 mar. 2017 e retificado em 01 jun. 2017.

. Lei ${ }^{\circ} \mathbf{1 3 . 6 8 0}$, de 14 de junho de 2018. Altera a Lei $n^{\circ} 1.283$, de 18 de dezembro de 1950, para dispor sobre o processo de fiscalização de produtos alimentícios de origem animal produzidos de forma artesanal. Diário Oficial da União. Brasília. 15 jun. 2018.

. Decreto $n^{\circ}$ 9.918, de 18 de julho de 2019. Regulamenta o art. 10-A da Lei $n^{\circ}$ 1.283, de 18 de dezembro de 1950, que dispõe sobre o processo de fiscalização de produtos alimentícios de origem animal produzidos de forma artesanal. Diário Oficial da União, Brasília. 19 jul. $2019 a$.

. Instrução Normativa do MAPA n ${ }^{\circ}$ 73, de 23 de dezembro de 2019.

Estabelece o Regulamento Técnico de Boas Práticas Agropecuárias destinadas aos produtores rurais fornecedores de leite para a fabricação de produtos lácteos artesanais, necessárias à concessão do selo ARTE. Diário Oficial de União, Brasília. 30 dez. 2019b.

BARATA, M. Formação histórica do Pará: obras reunidas. Coleção Amazônia. Belém: UFPA, 1973.

BOSI, E. A pesquisa em memória social. Psicologia USP, v. 4, n. 1/2, p. 277-284, 1993.

CRUZ, B. E. V. O Alvorecer das indicações geográficas na Amazônia: a "corrida" pela IG do queijo artesanal no Marajó, PA. Tese (Doutorado em Geografia) Universidade Estadual Paulista, Faculdade de Ciências e Tecnologia, Presidente Prudente: SP, 2017.

CRUZ, F. T. Produtos, consumidores e valorização de produtos tradicionais: um estudo sobre a qualidade dos alimentos a partir do caso do queijo serrano dos Campos de Cima da Serra - RS. Tese (Doutorado em Desenvolvimento Rural): Universidade Federal do Rio Grande do Sul, Faculdade de Ciências Econômicas, Porto Alegre: RS, 2012.

Agricultura familiar e processamento de alimentos: avanços e retrocessos na regulamentação de alimentos tradicionais. Revista de Economia e Sociologia Rural (in press), 2020. 
CRUZ, F. T; MENASCHE, R. Tradition and diversity jeopardised by food safety regulations? The Serrano cheese case, Campos de Cima da Serra region, Brazil. Food Policy, n. 45, p. 116-124, 2014.

FIGUEIRA, A.; QUADROS, M. Queijo do Marajó: começa a fase industrial. Revista Agroamazônia. Belém, n. 3, p. 36-37, 2002.

FONTE, M. knowledge, food and place: a way of producing, a way of knowing. Sociologia Ruralis, Rio de Janeiro, v. 48, n. 3, p. 200-222, 2008.

GOODMAN, D. The quality 'turn' and alternative food practices: reflections and agenda. Journal of Rural Studies. n, 19, p. 1-7, 2003.

GOODMAN, D.; DUPUIS, M. E., GOODMAN, M. K. Alternative food networks: knowledge, practice, and politics. Abingdon: Routledge, 2012.

GUERRERO, L. et al. Perception of traditional food products in six Europeans regions using free word association. Food quality and Preference, n. 21, p. 225-233, 2010.

HARVEY, M.; MCMEEKIN, A.; WARDE, A. (Ed.). Qualities of food. New York: Palgrave, 2004.

IBGE. Censo Demográfico 1991: Resultados preliminares. Rio de Janeiro: IBGE, 1992. . Sistema IBGE de Recuperação Automática - SIDRA, 2015. . Divisão regional do Brasil em regiões geográficas imediatas e regiões geográficas intermediárias, Coordenação de Geografia. - Rio de Janeiro: IBGE, 2017.

LANG, T.; BARLING, D.; CARAHER, M. Food policy: integrating health, environment and society. UK: Oxford University Press, 2009.

LIMA, E. de F. N. Extrativismo e produção de alimentos: Belém e o "núcleo subsidiário" de Marajó, 1850/1920. Estudos Sociedade e Agricultura. Rio de Janeiro n. 7, p. 59-89, 1996.

LISBOA, P. L. B. A terra dos Aruã: uma história ecológica do arquipélago do Marajó. Belém: Museu Paraense Emilio Goeldi, 2012.

MEIHY, J. C.; HOLANDA, F. História oral: como fazer, como pensar. São Paulo: Contexto, 2007.

MENASCHE, R. Campo e Cidade, comida e imaginário: percepções do rural à mesa. Ruris, Campinas: São Paulo. v. 03, n. 02, p. 195-218, 2010. 
MIRANDA NETO, M. J. Marajó: desafio da Amazônia, aspectos da reação a modelos exógenos de desenvolvimento. Rio de Janeiro, Record, 1976.

MURRIETA, R. S. S. Dialética do sabor: alimentação, ecologia e vida cotidiana em comunidades ribeirinhas da Ilha de Ituqui, Baixo Amazonas, Pará. Revista de Antropologia. São Paulo, v. 44 n. 02, p. 39-88, 2001.

NIEDERLE, P. A. Indicações Geográficas e processos de qualificação nos mercados agroalimentares. IN: NIEDERLE, Paulo André (Org). Indicações geográficas: qualidade e origem nos mercados alimentares. Porto Alegre: Editora da UFRGS, p. 23-53, 2013.

PARÁ. Lei 7.565, de 25 de outubro de 2011. Dispõe sobre normas para licenciamento de estabelecimentos processadores, registro e comercialização de produtos artesanais comestíveis de origem animal e vegetal no Estado do Pará, e dá outras providências. Diário Oficial do Estado do Pará. 26 out. 2011.

. Decreto $n^{\circ} 480$, de 12 de julho de 2012. Regulamenta a Lei $n^{\circ} 7.565$, de 25 de outubro de 2011, que dispõe sobre as normas para licenciamento de estabelecimentos processadores, registro e comercialização de produtos artesanais comestíveis de origem animal e vegetal no Estado do Pará e dá outras providências. Diário Oficial do Estado do Pará. 16 jul. 2012.

. Portaria ADEPARÁ $n^{\circ}$ 418, de 04 de março de 2013. Aprova o regulamento técnico de produção do queijo do Marajó e dá outras providências. Diário Oficial do Estado do Pará. 06 mar. 2013.

. Decreto $n^{\circ} 1.380$, de 3 de setembro de 2015. Regulamenta a Lei $n^{\circ} 7.565$, de 25 de outubro de 2011, que dispõe sobre as normas para licenciamento de estabelecimentos processadores, registro e comercialização de produtos artesanais comestíveis de origem animal e vegetal no Estado do Pará e dá outras providências. Diário Oficial do Estado do Pará. 04 set. 2015.

POULAIN, J.; PROENÇA, R. P. C.. Reflexões metodológicas para o estudo das práticas alimentares. Revista de Nutrição, Campinas, v. 16, n. 04, p. 365-386, 2003.

PREZOTTO, L. L. Sustentabilidade da agricultura familiar: implicações da legislação sanitária. Fortaleza: Fundação Konrad Adenauer, Instituto de Assessoria para o desenvolvimento humano, 2005.

SEIXAS, V. N. C. et al. Diagnóstico socioeconômico dos produtores de queijos do Marajó. Revista do Instituto Laticínios Cândido Tostes. v. 69, n. 5, p. 309-321, 2014. WILKINSON, J.; MIOR, L. C. Setor informal, produção familiar e pequena agroindústria: interfaces. Estudos Sociedade e Agricultura, Rio de Janeiro, n. 13, p. p. 29-45, 1999. 
Benedito Ely Valente da Cruz. Doutor em Geografia. Professor na Universidade do Estado do Pará. Departamento de Filosofia e Ciências Humanas, Universidade do Estado do Pará, CEP 66.050-540, Belém-Pará, Brasil. bvalente7@yahoo.com.br

Elcio Costa do Nascimento. Doutorando em Desenvolvimento Rural. Universidade Federal do Rio Grande do Sul. Rua São Domingos, Passagem Canaã, 628. Belém/PA, CEP66077-005. elcioncosta@gmail.com

Fabiana Thomé da Cruz. Doutora em Desenvolvimento Rural. Professora na Universidade Federal do Rio Grande do Sul. Av. João Pessoa, 31. Porto Alegre/RS, CEP90040-000. fabianathomedacruz@gmail.com

Miquéias Freitas Calvi. Doutor em Ambiente e Sociedade. Professor da Universidade Federal do Pará. Cargo. Faculdade de Engenharia Florestal/Departamento de Floresta, Universidade Federal do Pará, CEP 68372040, Altamira-Pará, Brasil. Miqueiascalvi3@gmail.com

Como citar: CRUZ, Benedito Ely Valente da et al. Redes sociais e preservação dos modos de produção de queijos artesanais da Ilha do Marajó, PA. Redes (St. Cruz Sul, Online), Santa Cruz do Sul, v. 25, n. 2, p. 506-526, abr. 2020. ISSN 1982-6745. Disponível em: https://online.unisc.br/seer/index.php/redes/article/view/14855 Acesso em: 15 maio 2020. doi: https://doi.org/10.17058/redes.v25i2.14855

\section{CONTRIBUIÇÃO DE CADA AUTOR}

a. Fundamentação teórico-conceitual e problematização: Elcio Costa do Nascimento, Fabiana Thomé da Cruz, Benedito Ely Valente da Cruz, Miquéias Freitas Calvi.

b. Pesquisa de dados e análise estatística: Elcio Costa do Nascimento, Benedito Ely Valente da Cruz.

c. Elaboração de figuras e tabelas: não se aplica

d. Fotos: Elcio Costa do Nascimento

e. Elaboração e redação do texto: Elcio Costa do Nascimento, Benedito Ely Valente da Cruz, Fabiana Thomé da Cruz, Miquéias Freitas Calvi.

f. Seleção das referências bibliográficas: Elcio Costa do Nascimento, Fabiana Thomé da cruz.

Fontes de financiamento: Conselho Nacional de Desenvolvimento Científico e Tecnológico CNPq; Ministério do Desenvolvimento Agrário - MDA. 